\title{
Library Escape Room
}

Dora Rowe, Union Presbyterian Seminary

\begin{abstract}
Gamification techniques have become very popular as tools of library instruction. Union Presbyterian Seminary developed an escape room as a voluntary information literacy program. Our goals were to help students hone their skills with the library's databases, discover resources within the reference room, reinforce their citation skills, and remind them that finding information is fun.

Creating the escape room began with an idea and ended with its assessment and plans to offer it again. In between was a process in which we learned how to develop the story and build the necessary structures, as well as market and host the event.
\end{abstract}

\section{INTRODUCTION}

It is sometimes a challenge to get timely library instruction to students in a way that will engage them when they are already working towards masters and doctoral degrees. Given the trends towards non-directed and "fun" ways to encourage learning and library usage, we on the Richmond campus of Union Presbyterian Seminary have begun adding voluntary, story-driven information literacy events to our repertory of offerings.

One of our first endeavors was our library escape room. We began planning it over the summer of 2018, and it debuted in February 2019. We held it in the reference room and used the tools already in the room as both props and hint-makers. We only wanted a few participants for the first time, but in our minds from the beginning was the hope that we could use the plan again for our Fall Student Orientation. We designed it to be a fun evening with the ulterior purpose of encouraging use of the reference room and providing students with a non-linear opportunity to reinforce their research skills.

We began by outlining the idea to library administration. Given our limited resources, we justified the program by aligning it to library 
instruction. In general, escape rooms can offer several benefits with respect to education. Even when they are offered strictly as entertainment, they create social cohesion and help to relieve stress. However, adding an information literacy component convinced our seminary librarian that this was a good use of both our time and budget.

\section{RESEARCH PHASE}

Once approval was firmly in place, we began to research how to develop a challenging but enjoyable escape room. Since not everyone on our team had actually participated in one, the first thing was to visit a well-reviewed professional escape room. We took mental notes while we were struggling with the puzzles and locks. Luckily, in the end we all escaped!

We went online for the next phase of research. Watching a season's worth of "Escape! With Janet Varney" from the Geek and Sundry YouTube site allowed us to recognize patterns and similarities in the types of puzzles. ${ }^{1}$ We also used several different instructional and "DIY" sites to round out the first phase our research.

Armed with this, we went in search of librarians with some experience with similar outreach programs. The permanent escape room hosted by one of our local academic libraries, Walter M. Bortz III Library at Hampden-Sydney College, was consistently mentioned as a resource. We contacted Maryśka Connolly-Brown and interviewed her when we toured the Bortz Escape Room.

Several years ago, Bortz Library dedicated a storage area to the permanent installation of an escape room open to the whole campus community for a fee. They built three rooms in the space and developed the first story with little budget for more than locks and boxes. It proved so popular that they currently mount a different story with new puzzles every year, and it has become not just self-funding, but they use excess proceeds to fund other special projects within the library. ${ }^{2}$

Managing realistic expectations was one of Ms. Connolly-Brown's nuggets. She concurred with the professional escape room's group size limits of no more than eight people and no fewer than three or four. She suggested that the library should get as much institutional buy-in for the project as possible. And finally, the room should be complex 
enough to be challenging, but not so difficult as to be impossible to complete in an hour. ${ }^{3}$

The final step in the research phase was to build an initial budget for approval. We brainstormed what we thought we should buy, based on what we had seen and questions that we had asked of Ms. ConnollyBrown. We knew we would need a variety of locks and boxes, to hold clues and other objects. We wanted black lights and marker pens, because as Ms. Connolly-Brown had said, "Black light flashlights are just cool!" ${ }^{4}$ We needed decorations and office supplies, and, finally, we set aside a little extra for incidentals that we hadn't considered. In the end, we budgeted $\$ 300$.

\section{DEVELOPING THE STORY}

The heart of the escape room is the story that frames it. It needs to be simple and easy to adapt, but like any story, it should have a beginning, a middle, and an end. Since it will be completely interactive, we felt that a highly structured script would be a mistake, especially since we needed to be able to improvise hints to our students. And we wanted all of the clues and puzzles to tie together the different rooms we designed.

We started with a storyboard. We mapped the reference room first, then a little entry area next to it which we converted into an office for the event. In retrospect, we probably should have used graph paper and made it to scale, but we just made rough sketches of the different areas. We used these then to design the flow of the story, much like we would chart a theatrical scene.

Once we had a clear story, we needed to assign roles to our team. One of our team volunteered to be our artist, and used a mix of charcoals and Sharpie markers to create pictures that acted as both clues and ambience. We needed someone (or several people) to engineer the extra room, although we planned to ask the Seminary Physical Plant for the actual construction. We decided to ask one of the student workers to help us set up and tear down, while one of the librarians would act as the hinter and the "mad librarian."

After the roles were assigned, we identified the supplies we needed and began to build the shopping lists online. Also, we found multimedia 
blank art canvases, as well as poster board, markers and pens, at a local art supply store. Our artist used many of her own materials, such as charcoal pens and Sharpie markers. We requisitioned basic office supplies like tape, glue, and staples from the library's supply cabinet, and lastly, we went "shopping" in the library's storage areas for old equipment, clocks, desks, file cabinets, and other items that made excellent window dressing for our stage design.

\section{CREATING THE PUZZLES}

Once the story is developed and fleshed out, the next step is creating the puzzles. Yet again, having multiple people on the team is very helpful. The key to a truly memorable escape room is to design things for many different types of learning styles. Some should be easy, some deceptively easy, and some very challenging. Similarly, we found that visual puzzles, physical puzzles, logic puzzles, and even old-fashioned jigsaw puzzles are popular. While creating all of this, we kept the clues written as if dictated by our mad librarian.

A critical point, however, was that our puzzles needed to use a skill that we were highlighting. We went to the ACRL Framework for Information Literacy and assigned specific practices to encourage dispositions. ${ }^{5}$ We also asked our colleagues what one or two things their imaginary perfect student would know. Then we created puzzles around the feedback and suggestions.

The reference librarian provided us with a list of resources that she wanted us to highlight. While she knew that she gave more than we needed, the list formed the backbone of clue locations. We placed guide handouts for searching the databases and the catalog in different books, as well as individual items needed to escape. We took a discarded newspaper and hid clues in it, both with invisible writing and in a simple underlining code.

We decided early on to address the online elephant in the room. Several of the puzzles required the use of our databases and the fulltext finder. We also wanted them to use the catalog. So, we set up a spare individual printer on one of the computers. The puzzles themselves required students to find clues to specific titles of books and articles, as well the title of one journal from its ISSN. 
Again, though, we really wanted the puzzles to reflect the multiple intelligences that characterize our students. For example, we used tangrams, pre-made puzzle boxes, and the secret writing for those who learn best kinesthetically, and therefore were better with puzzles that they could physically manipulate. The tangram puzzle, once completed, provided a graphic clue for a visual learner, as do codes hidden in pictures and deciphering clues in the secret writing. Logical thinkers really appreciated our chess puzzles and traditional logic puzzles. Our verbal and written learners excelled with riddles and substitution codes.

Once they were written, we listed the puzzles in a chart. We listed the clue to solve it, the location of both the puzzle and the clue, and then the location of the clue. We included the text of the clues, even though each one was handwritten, as if our librarian was in the habit of writing notes to herself, then losing them. Doing this meant that we could, at a day's notice, set up the room and always have it play the same.

After all of this was done, we finished off our shopping list and purchased the items. We bought most of the tools and locks from a large online warehouse store. We also found some things from a traditional office supply store, from discount stores, and an art store. However, we found quite a bit hiding in storage and even in library staff members' homes.

\section{CONSTRUCTING THE ROOM}

Since we wanted the students to begin in the back of the atrium of the library, we needed to create a faux closure as a visual break hiding the rest of the library. We didn't want to use a true physically built structure. Therefore, we created a "wall" made from two dark brown twin bed sheets and hung them from the ceiling using pencils, binder clips and fishing line.

While the ideal wall construction would be the large display panels used for artistic and other exhibitions-they are about 6' 6 " in height-most of those panels were in use for a photographic installation. Therefore, we only had one two-board panel that could be used. However, by placing it next to the corner of the alcove leading into the 
reference room, we created the illusion of an actual room.

Otherwise, we used the reference room without much change. We hosted the room in the evening after the library closed, but we remained mindful that patrons would expect an orderly area the following morning. We used existing aspects of the room, such as the lifting shelves for the back issues of periodicals, the seating areas, and the occasional tables.

Using the storyboard and the chart, we placed the pictures, the boxes, and the clues. This took longer than we expected, but having the visual representation was essential. Well-chosen sounds increased the ambience and the tension, so we played the base sound of a clock ticking in the background. Once we finally locked both doors, we were ready to invite our students to try to escape.

\section{RUNNING THE ROOM}

Because we wanted a small group, we only advertised through campus email and on the private campus Facebook page. We also attended the seminary's weekly gathering and personally invited students. Finally, we encouraged our student assistants to "talk it up."

Before we hosted it for real, we invited several students to test our puzzles. Following them and taking notes to find the places where they struggled allowed us to fix issues. Beta testing the entire escape room is a must. It's the only way to find things that don't go correctly or discover badly worded clues and puzzles. ${ }^{6}$

When show day finally came, we set up the room, and then went out to meet our guests. We discovered that going over our simple rules made the best start. Don't destroy the room. Don't put away the used books. Recognize where the exits are, because we can't actually lock anyone up. Then, we gave the introduction to the story, stepped back, and let them begin.

One thing that we learned is that we have a tendency to want to hint. of course, our primary intention is to help them escape, because the actual purpose is for them to use their research skills to help them solve the puzzles. However, our room ended up being very challenging-"as hard as the hard rooms I've paid to do," said one of our reviews!-so having a free hand with the clues assured that everyone escaped. 


\section{ASSESSMENTS}

As enjoyable as the escape room was, at the end we needed to assess whether the program was successful from a library standpoint. We had several assessment tools at our disposal for our programs. In general, for our many programs we would choose between surveys, exit interviews, and analyzing our usage statistics several weeks after the program.

The students that participated gave glowing reviews. They told not just us, but other people on campus as well. They felt that the room was challenging and well-designed, and that it had an engaging story that was integrated throughout the rooms. Nothing felt rushed, nor did they get the sense that they were just completing puzzles for no reason.

However, they also felt that they were not the best target audience for this specific scenario. They were more advanced students, some in their last semester. While the night was "a good refresher of the texts in the Reference Room," and while they learned a couple of incidental things, they didn't feel that they were introduced to any new material or concepts related to research or using the library in general and the reference room in particular. They all agreed that this particular escape room should be made a part of our standard New Student Orientation.

We performed neither pre- nor post-event assessment surveys with this initial group. Using their feedback, we approached Student Services about adding a voluntary evening session several nights of our Orientation Week. We did pre-event and post-event assessment on these nights. We had mainly positive comments, with students saying that they felt far more confident about using the library and more aware of what we offered.

The only negative feedback came the evening that the event was overscheduled. Too many people made the teamwork diffuse, and that game took far longer than the hour that was planned. Again, we did not want students to fail to escape in this specific scenario, so we added to their time. Even the students who provided that feedback said that they would enjoy doing a new scenario highlighting a different section of the library, as long as we enforced a stricter limit on participants. 


\section{GOING FORWARD}

While we still don't have complete usage statistics yet, anecdotal evidence is suggesting that introducing the escape room in Orientation has worked. Our reference librarian has reported a substantial increase in students using her services in the first month of the semester. While it is not likely entirely attributable to the escape room event, as only half of our incoming class elected to participate, most of those students did report an increased feeling of comfort using our reference resources.

In future years, we may tweak the storyline to keep it relevant, but "Escape the Mad Librarian" will likely remain a staple of our New Student Orientation. We will provide Student Services with a little more guidance on how we would like them to address over-scheduling. That way we will ensure that we maintain a limited number of participants in each group.

Gamification of library instruction seems to have worked, and we will continue to add offerings of this type of program to our more traditional menu of workshops and in-class sessions. We are beginning to prepare another escape scenario, this time highlighting our audiovisual collection and our new makerspace. We are also exploring other avenues of non-structured information literacy programs intended to teach research skills while providing an entertaining background. 


\section{ENDNOTES}

1 Escape! With Janet Varney, produced by Geek and Sundry, 2017, https://www.youtube.com/playlist?list=PL7atuZxmT957 N402Jp3bMXmq_Y7J-mK-.

2 Maryśka Connolly-Brown, interview by Dora Rowe, "Running an Escape Room in an Academic Library” (unpublished), December 13, 2018.

3 Connolly-Brown.

4 Connolly-Brown.

5 Association of College and Research Libraries, "Framework for Information Literacy for Higher Education,” January 11, 2016, http://www.ala.org/acrl/standards/ilframework.

6 Marc Hight and Maryśka Connolly-Brown, "Designing an Escape Room,” prezi.com, November 26, 2018, https://prezi. com/qmyjdw7c98uu/designing-an-escape-room. 